Volume 2

Number 2 Teaching Secrecy

January 2021

\title{
Revealing Challenges of Teaching Secrecy
}

\author{
Jack Z. Bratich \\ Rutgers University - New Brunswick, jbratich@comminfo.rutgers.edu \\ Craig R. Scott \\ Rutgers University - New Brunswick, crscott@rutgers.edu
}

Follow this and additional works at: https://scholarworks.sjsu.edu/secrecyandsociety

Part of the Critical and Cultural Studies Commons, Interpersonal and Small Group Communication Commons, Organizational Communication Commons, and the Other Communication Commons

\section{Recommended Citation}

Bratich, Jack Z. and Craig R. Scott. 2021. "Revealing Challenges of Teaching Secrecy." Secrecy and Society 2(2). https://doi.org/10.31979/2377-6188.2021.020203

https://scholarworks.sjsu.edu/secrecyandsociety/vol2/iss2/3

This Special Issue Article is brought to you for free and open access by the School of Information at SJSU ScholarWorks. It has been accepted for inclusion in Secrecy and Society by an authorized administrator of SJSU ScholarWorks. For more information, please contact scholarworks@sjsu.edu. 


\title{
Revealing Challenges of Teaching Secrecy
}

\begin{abstract}
All teaching has something to do with transmission of hidden knowledge, secrecy, and revelation. But the teaching of secrecy itself faces particular challenges. Drawing on the authors' experiences teaching secrecy-themed seminars to first-year university students, this paper pinpoints four such challenges: how to determine the range of phenomena to cover in a short course, how to prevent excessive interpretation of secrets, how to encourage students to take a fun topic with seriousness, and how to engage students in their own practices of secrecy. In laying out these challenges, we aim to contribute to a secrecy literacy: a needed competency so people can better evaluate efforts to keep secrets and appreciate the need for certain types of secrets while also being able to critique problematic forms. This secrecy literacy can provide a foundation for the skills needed to better manage secrecy in our professional and everyday lives.
\end{abstract}

Keywords

anonymity, literacy, pedagogy, secrecy, teaching, transparency 


\title{
Revealing Challenges of Teaching Secrecy
}

Jack Z. Bratich and Craig R. Scott

\begin{abstract}
All teaching has something to do with transmission of hidden knowledge, secrecy, and revelation. But the teaching of secrecy itself faces particular challenges. Drawing on the authors' experiences teaching secrecy-themed seminars to first-year university students, this paper pinpoints four such challenges: how to determine the range of phenomena to cover in a short course, how to prevent excessive interpretation of secrets, how to encourage students to take a fun and familiar, and how to engage students in their own practices of secrecy. In laying out these challenges, we aim to contribute to a secrecy literacy: a needed competency so people can better evaluate efforts to keep secrets, and appreciate the need for certain types of secrets while also being able to critique problematic forms. Such experiments in the pedagogies of secrecy aim to provide a foundation for the skills needed to better manage secrecy in our professional and everyday lives.
\end{abstract}

Keywords: anonymity, literacy, pedagogy, secrecy, teaching, transparency

The usage of secrets and secrecy represents an enduring social phenomenon that has intrigued people for ages. Defined as intentional concealment (Bok 1982), secrecy is a key means by which we shape our own and others' identities. Whether used for fun/play, as a means of protecting certain forms of knowledge for a competitive advantage over others, or as a way to conceal wrongdoing, its use can be highly consequential. As rhetorical scholar Edwin Black (1988) notes, secrets are 
prized possessions and people may go to great lengths to keep them secure. He argues that we as a society often dislike secrecy but do not entirely welcome full disclosure either. Maret (2016) describes secrecy as a wicked social problem that demands greater scholarly attention.

Although scholars from a range of disciplines have begun to research secrets and secrecy in greater detail, that has not yet translated into teaching about secrecy. In some ways this is surprising because teaching has long been associated with revelation and secrecy. From "secret teachings" to opening students' eyes to new truths, to pedagogy as initiation into Mysteries, secrecy has been more than a course's content - it is the form of teaching itself. Yet, published works about "teaching secrecy" have to date been focused mostly on "faculty refusal to provide colleagues with information and materials relevant to the role of college teaching" (Braxton and Bayer 1999, 62; see also Nagle 2013). What seem to be missing are broader discussions of how we can educate people about secrecy to:

- create a needed competency so people can better evaluate efforts to keep secrets

- appreciate the need for certain types of proprietary and intellectual secrets while also being able to critique other corporate and government secrets that conceal wrongdoing 
- provide a foundation for the skills needed by citizens and certain type of workers to keep and recognize secrets as we seek to better manage secrecy in our professional and everyday lives.

As some experts have argued, teaching secrecy "literacy" across levels of society is important for creating an informed citizenry in an information age (Maret 2016).

Part of our motivation in writing this essay is our own experience in trying to better understand and then teach about secrets and secrecy. Not only are we researchers interested in this topic, but we have co-taught a 1credit course on Secrecy, Transparency, and (In)Visibility as part of a program where first-year students get exposed to scholarly research in small 20-person classes at our university. We have individually taught other courses on privacy, privacy and secrecy, conspiracy theories, and anonymity/identity. Collectively, these experiences help to position us to discuss several challenges related to the teaching of secrecy. We organize this essay around four key challenges related to teaching about secrecy and then conclude with a few overall observations hopefully of value to others interested in this issue.

\section{Challenge 1: Breadth and Depth of Course Coverage}

Part of the challenge with a topic like secrets and secrecy is determining the scope of the course. On the one hand, it is tempting to try 
and cover everything - because this is likely to be the only course on secrets and/or secrecy that may be offered in most programs. On the other hand, actual research on and established knowledge about secrecy may still be somewhat limited-and some of what does exist may be far enough outside one's own expertise that it is difficult to teach about all of it. Further complicating all this is the decision about whether to include related ideas such as privacy, anonymity, and confidentiality (as well as disclosure, openness, and transparency).

While some of the above are common challenges to teaching any material, we want to highlight a couple of them that are specific to secrecy. Secrecy is something that is profoundly interdisciplinary, spanning a wide range of angles and approaches to consider. Canonical texts in the core disciplines of psychology, anthropology, sociology, political science, and philosophy have wrangled with secrecy as an ethical, individual, cultural, political, and social phenomena. Even the often-paired concept publicity hasn't had that kind of coverage. Add to this that our respective fields are communication and media studies, and we had quite a lot to manage (especially for a one-hour weekly pass/fail course).

In addition, while any pedagogical practice must take care to respect students' private worlds, teaching secrecy poses a special challenge. How do we create the conditions for students to speak sincerely, even frankly, about delicate matters related to family, romantic relationships, friends, and 
institutional authorities? Are we as teachers taking on surveillance roles when we solicit their (perhaps secret) thoughts about secrecy? In an era where having something to hide is tied to shame, even criminality, how do we foster beneficial and productive intellectual conversations to explore what could be construed as taboos?

Our own experience suggests a few potentially useful strategies. First, narrow the course focus in a way that capitalizes on your own scholarly strengths while still providing a reasonably broad introduction to the topic. For us, that meant taking a communication-based view of secrecy given our training and given the inherently communicative nature of a construct like secrecy. A second strategy we had the luxury of using was team teaching because even within communication there are a wide range of useful perspectives on secrets and secrecy. That team-based approach can also be a strategy for bringing in views that incorporate multiple disciplines.

Perhaps the most useful strategy for managing the breadth/depth challenge was to select key "levels" where secrecy played out - especially the interpersonal, organizational, and societal/cultural. At the interpersonal level (see Caughlin et al. 2000; Vangelisti, Caughlin, and Timmerman 2001), we linked secrecy to those other personal and relational level concerns of disclosure and privacy management; furthermore, we discussed the role of secrets in various types of family and other relationships. Many students in our seminar were clearly most interested in interpersonal secrets. This is not 
surprising, given that the course is open only to first-year undergraduates, a population that is encountering new people and experiencing new things that prompt them to question the ways they perform their selfhood. This is a time of their lives to (re)fashion themselves - raising all sorts of practical and ethical questions about what they tell new people about themselves and what they keep to themselves, what aspects of this new experience to share with high school friends and family, what should be shared between romantic partners, how one finds trust circles with whom to share their views and emotions amid the whirlwind that is life at a massive public university, and so much more.

At another level, so many important issues surrounding secrecy are tied to various organizations. Thus, we discussed secret societies and other hidden organizations (see Scott 2013; Stohl and Stohl 2011). We examined various forms of workplace secrecy and discussed whistleblowing and other disclosures of corporate wrongdoing (see Costas and Grey 2016). Though students often had less direct experience with secrecy at this level, they recognized the importance of considering organizations as they prepared for internships, engaged in various forms of work while in school, and ultimately evaluated occupations and employers they might join upon graduation.

Another very important level of secrets and secrecy is at a more societal/cultural level (Simmel 1906). Thus, we attempted to examine the ways in which we are surrounded by secrecy in media culture through ads, 
games, films, tv shows, websites, corporate logos, museums, memes, cultural figures like Mr. X and Deep Throat, etc. Related to this, we examined secrecy in pop culture and how it attempts to render secrecy visible and even spectacular. We included an examination of the occult and popular occulture that helps one to attune to the hidden and shadowy in society - including the existence of public secrecy (see Bratich 2007). At this cultural/societal level, the management of secrecy and revelation is done through cultural narratives and a recognition that revelations often add mysteries rather than dispel them. Many students had not thought much about secrecy at this level - making the topics examined here highly informative to them. There are, of course, other levels (e.g., small group, international) and contexts (e.g., political, healthcare) one could choose to examine - but focusing on a few key levels can be useful for managing the breadth and depth of this topic.

\section{Challenge 2: Avoiding Seeing Secrecy Everywhere}

Secrets are tempting objects of knowledge, especially when we encounter them through leaks, revelations, or even further occlusions. We have seen students get excited about pop culture narratives featuring coded communications, whether related to spying or secret societies' public displays of esoteric symbols. Once we start looking for secrets, they can expand into an infinite horizon. To echo the title of a Massachusetts School 
of Law Journal issue, "secrecy is everywhere." Given its form and circulation, as Clare Birchall $(2016,1)$ puts it, we "may never catch up with the secret 'itself."' This may be especially challenging if one takes a generally broad approach to secrecy, as we have generally advocated.

Thus one of the challenges to teaching secrecy is revealing to students that secrecy is everywhere while avoiding slipping into over-interpretation where nearly everything is viewed as a secret. If education is less about transmission of knowledge than about encouraging discovery as well as fostering cognitive, ethical and social growth, then we need a secrecy pedagogy in tune with the latter. We wanted to offer a literacy whereby students become aware of, and really sense, secrecy around them. But, we also wanted to cultivate such a perception of the secret without lapsing into hyper-interpretation, obsession, and even paranoia. This challenge could be considered a distilled version of other critical pedagogical challenges: becoming aware of the world's processes without succumbing to pessimism and inaction.

How do we as instructors and students of secrecy put the brakes on spiraling out when it comes to interpreting signs and secret influences? We can start with Birchall's $(2014,29)$ provocation and invitation to "'stay with' and 'encounter' the secret rather than positioning it as a problem to be solved." We reorient ourselves away "from a hermeneutics of the secret to an aesthetics of the secret" (29). This means cultivating sensibilities in a self 
that is attuned to secrecy, that recognizes secrecy's complexities (rather than just banishing it), and that "stay[s] with the secret as secret, instead of moving too quickly towards revelation" (26). It means fostering an analytic approach that assesses layers of types, reasons, actors, and effects of secrecy and revelation while remaining open to possibilities and discoveries. And it invites a patience with, and a listening to, the non-communicated as a way of building worlds together: "what forms of politics, ethics, of being-incommon, might it be possible to think if we pay attention to secrecy" (Birchall 2011, 61)? Paying attention to secrecy encourages a literacy to appreciate and evaluate secrecy and its limits. Such an initial pedagogic orientation would follow Walter Benjamin's $(1977,31)$ definition of truth as "not a matter of exposure which destroys the secret, but a revelation which does justice to it."

\section{Challenge 3: Taking a Fun Topic Seriously}

As we noted at the outset, secrets/secrecy is a "fun" topic that likely attracted students to the course. Several of the subtopics we examined (e.g., secret societies, secrecy in pop culture and the media) are also fun and entertaining in nature. Although there are obvious benefits to teaching such topics, there is also a danger that students may be less inclined to treat it seriously and as a result may not recognize the non-trivial consequences linked to secrecy in our society and in our daily lives. Drawing from our 
Secrecy and Society, Vol. 2, No. 2 [2021], Art. 3

discussion of secrecy literacy above, we could say that staying with the secret, even doing justice to it, means recognizing the myriad forms - fun without being frivolous, playful without becoming trivial - that make secrecy significant.

To confront that, one of our strategies was to try and ground content and discussions as much as possible in existing scholarly research, broadly defined. Being able to talk about our own and others' research into these issues provided credibility and helped highlight the consequential nature of secrecy. We assigned some reading from our own work (see Bratich 2006; Scott 2013), but we also designed a week where students read original research articles and summarized those for the course. Among those chosen by students were articles about keeping secrets from parents (Frijns et al. 2005), the diversity of secrets people have (see Slepian, Chun, \& Mason 2017), secrecy and marriage (Finkenauer \& Hazam 2000), governments and media transparency (see Klyueva and Tsetsura 2010), financial secrecy (Tax Justice Network 2018), and technology and secrecy (Hables Gray 2016). In each instance, students summarized what the study set out to do, noted the methods used, and provided a summary of the key findings of the study.

Perhaps equally important, we designed our co-taught course (and have done this with other related classes as well) so that students had to engage in some of their own original scholarly research into the topic as well. Although we did not seek to publish this work or share it beyond the 
class, we did intend to introduce students to the idea of conducting original research - and in the process help them see how one might actually investigate a topic like secrets/secrecy in a scholarly way. Thus, we asked each student or student pair to initially select a secrecy issue/topic (e.g., interpersonal secrecy, family secrets, secrecy vs. privacy, leaks, whistleblowing, workplace secrecy, trade/proprietary secrets, secret government classifications, secret societies, secret cults, public secrets, etc.). Next, students were to write up a proposal about the "importance" of the topic, a "research question" (or two) about this issue/topic, and a "procedure" to be used to explore this issue. The research questions could be simple descriptive questions (e.g., what are the key secrecy concerns raised by intelligence agencies?), ones that attempt to relate secrecy to other topics (e.g., how does one's need for secrecy affect the use of various social media platforms?), ones that compare various social groups on secrecy issues (e.g., do millennials and baby boomers differ in their concerns about workplace secrecy?), or ones that take some issue or document and perform some sort of critical scholarly analysis or content analysis to answer questions (e.g., what views of secrecy are found in popular media coverage of $X$ event?). We briefly discussed with students some of the challenges of researching a topic like secrecy (and when and how one might talk about things they often wished to keep secret) and then provided them guidelines for one of four methods to use for their small-scale research effort: 
- Interviews of 2-4 people who may be experts or have unique knowledge of a secrecy-relevant topic

- Short survey questionnaires filled out by $10+$ people to assess their attitudes or have them report their behaviors

- Analysis of content in existing secrecy-related artifacts (news articles, webpages, comic books, video games, narrative films, detective shows, music videos, advertisements, blog posts, etc.) to count occurrences or explore underlying patterns

- Critical scholarly assessment of some secrecy-related issue, event, or document to identify tensions/problems/themes, and place them in a broader social, political and cultural context

After students gathered their data and did some basic analysis, they then shared their findings in formal presentations to the class. With the shortened 1 -credit classes we only required the formal presentation. For a more intensive class, a written paper could be used to report findings as well. In both cases, the original findings and conclusions were presented in the context of existing theory/research about that particular issue of secrecy. We believe an assignment like this allowed most students to still select some aspect of secrecy that interested them - but then better understand that issue in a more serious, scholarly way. The celebratory 
nature of the final research presentations day helped to recognize that secrecy is indeed a fun, and serious, topic.

\section{Challenge 4: Secretly Engaging Students}

Even in a course on a topic like secrets/secrecy, one still has to be engaging in the approach to the course if you expect students to focus on the topic at hand and feel like contributing. We have attempted to do this in several ways related to the "secret" nature of the course. We began class gatherings with some song about "secrets" (e.g., Dirty Little Secret by All American Rejects, Secrets by One Republic, Do You Want to Know a Secret? by the Beatles, Secret Agent Man by Johnny Rivers, and Madonna's Secret) to welcome students in and set the tone for that session. We have brought in expert guest speakers, shown online video content about secrecy issues, and even included video footage of Edward Snowden who was speaking (virtually) at a secrecy conference we had both attended. Our location also afforded us the opportunity to do field trips - most notably to the Spyscape Museum in New York City - that brought to life some of the topics being addressed in class.

Additionally, we tried to design the class with weekly experiences that typically required the students to do some activity outside class time and then post about it online before the following class. One of the weeks was simply about "revealing yourself" as a way to introduce oneself to the class. 
To make it more interesting we have asked students to include some secret about themselves that most others did not know and/or to share an example/story about secrecy that they find interesting. In some weeks we would ask students to post a summary of an assigned article or chapter with key takeaways to keep them engaged in the readings. We did something similar with movies or television episodes we wanted them to watch (e.g., Wormwood).

A more interesting and revealing activity was when we asked students to post an online secret. In some ways, this was done in the spirit of Warren's (2005) PostSecret art project, where people would anonymously share a secret via postcard. To build on this idea and provide a somewhat more interactive experience, we invited students to select one of five online tools available at the time (whisper, secretsanon, my secretpost, e-admit, or tellmysecret) and then post a secret to it. Consistent with Paxman's (2013) suggestion, we then asked the students to reflect on this experience by making a post about their impressions of the tool, the types of secrets they saw there, and their experience/feelings about posting the secret and reading others' secrets. We were careful not to ask students to necessarily reveal the secret they posted - because, as Paxman notes, the secrets can be very emotional for some students; but hearing about their impressions and their descriptions of the secrets that others had posted was informative. 
Another engaging activity was to have students find an organizational logo, advertisement, product, or service that is somehow linked to the occult or popular occulture and to then share relevant images and summarize the "secret" connection. Students made posts about Google, Gucci, MercedesBenz, Starbucks, Kellogg's, McDonald's, Shell, Chrysler, Walt Disney, and others. In another week we had students research and post about any secret society that interested them.

Although we had not planned it initially, one of the most engaging aspects of the class emerged as we were co-teaching the class in the Spring of 2018. During that time, the news was filled with stories surrounding congressional representative Devin Nunes' claims of an FBI conspiracy against the President (some called it a secret society within the Bureau). For a couple of weeks in February, the dizzying narrative involved the following: a special memo detailing FBI secret agents that was being kept hidden from the FBI itself, a secret visit by Nunes to the White House about the contents of the memo that was rendered "confidential" and thus not made public, a counter-memo, a secretly altered version of the memo, and a bipartisan battle over how to make this secret memo public, including a GOP-generated hashtag campaign \#ReleaseTheMemo (see Stanglin 2018).

These couple of weeks were emblematic of a presidential administration that was fixated on leaks and secret machinations - one that made secrecy newsworthy again (thus providing much material for 
teaching). Pundits called the Trump administration a "government by leak" and even a Leak War. The Trump administration was leaking so much that then Attorney General Jeff Sessions announced, "This culture of leaking must stop...And I have this warning for would-be leakers: don't do it." And in his brief stint as White House Communications Director, Anthony Scaramucci simultaneously announced the need for secret leaks and the need to stop them: "I understand we have to leak things to reporters to help shape policy or try to balloon things or do tests on ideas or people for different jobs. I'm talking about nefarious, unnecessary, backstabbing, palace intrigue-like leaks." Presidential supporters found a common name to describe the nefarious secret forces and shadow government conspiring against their leader: "deep state." We would regularly begin class with an update on the secretive aspects of these memos and other leaks and see what sense students were making of them. In our view, opportunities like this one to make the topic timely and closely connected with current events that students are (or perhaps should be) tuned into are likely to stimulate student engagement and thus enhance the overall quality of the course.

\section{Final Thoughts}

All education involves some aspect of secrecy (in the sense of turning the unknown into the known), but the teaching of secrecy itself faces particular challenges. Some of these challenges - such as breadth/depth of 
course coverage and keeping students engaged - are familiar across a range of courses; however, the topic of secrecy affords interesting options in terms of what to cover and for engaging students in creative ways. Other challenges - such as avoiding seeing secrecy everywhere and treating a fun topic seriously - are a bit more unique to topics like secrecy; thus, these challenges benefit from reasonable approaches that ground our understanding in actual research and in a recognition that not everything is about secrets.

These challenges have to be addressed so that we can realize the benefits of teaching about secrets and secrecy. For us, this very much involves the creation of a type of secrecy literacy. We would argue that in addition to or as part of one's media and communication literacy, students need literacies related to privacy, anonymity, and even secrecy. In one sense, a secrecy literacy involves exposing students to secrecy while not completely exposing secrecy. In other ways, this literacy is about being able to effectively and appropriately conceal and reveal secrets, being able to recognize and appreciate the need for secrecy and concealment in some situations and the need for disclosure and revelation in other contexts, and being able to manage one's secret messages and networks of confidants. Secrecy literacy can help create a broader understanding and awareness of secrecy that may help to ensure more socially acceptable uses of secrecy in our offline and online interactions. 
Teaching about secrecy and developing literacy around it can help solve some of the wicked societal problems that involve secrecy. Conversely, that literacy can help us to utilize secrecy responsibly in a world singlemindedly focused on surveillance and transparency as solutions to social and political ills. But that teaching and learning does not readily happen when too many challenges and barriers are in place. We hope that by sharing our not exactly secret (but hitherto-unpublicized) experiences of teaching secrecy and addressing what we see as four key challenges, we can add to the collective project of enhancing secrecy pedagogies.

\section{References}

Benjamin, Walter. 1977. The Origin of German Tragic Drama. Translated by John Osborne. London: New Left Books.

Birchall, Clare. 2011. "Transparency, Interrupted: Secrets of the Left." Theory, Culture \& Society 28, no. 7-8: 60-84. https://doi.org/10.1177/0263276411423040

Birchall, Clare. 2014. "Aesthetics of the Secret." New Formations 83: 2546. https://doi.org/10.1177/0263276411423040

Birchall, Clare. 2016. "Six Answers to the Question 'What is Secrecy Studies?'." Secrecy and Society 1, no. 1. https://scholarworks.sjsu.edu/secrecyandsociety/vol1/iss1/2

Black, Edwin. 1988. "Secrecy and disclosure as rhetorical forms." Quarterly Journal of Speech 74, no. 2: 133-150. https://doi.org/10.1080/00335638809383833

Bok, Sissela. 1982. Secrets: On the Ethics of Concealment and Revelation. New York: Pantheon Books. 
Bratich, Jack. 2007. "Popular Secrecy and Occultural Studies." Cultural Studies 21, no. 1: 42-58. https://doi.org/10.1080/09502380601046956

Bratich, Jack. 2006. "Public Secrecy and Immanent Security: A Strategic Analysis." Cultural Studies 20, no. 4-5: 493-511. https://doi.org/10.1080/09502380600708937

Braxton, John M. and Alan E. Bayer. 1999. Faculty Misconduct in Collegiate Teaching. Baltimore, MD: The Johns Hopkins University Press.

Caughlin, John P., Tamara D. Golish, Loreen N. Olson, Jack E. Sargent, Jeff S. Cook and Sandra Petronio. 2000. "Intrafamily Secrets in Various Family Configurations: A Communication Boundary Management Perspective." Communication Studies 51, no. 2: 116-134. https://doi.org/10.1080/10510970009388513

Costas, Jana and Christopher Grey. 2016. Secrecy at Work: The Hidden Architecture of Organizational Life. Stanford, CA: Stanford University.

Finkenauer, Catrin and Hana Hazam. 2000. "Disclosure and Secrecy in Marriage: Do Both Contribute to Marital Satisfaction?" Journal of Social and Personal Relationships 17, no. 2: 245-263. https://doi.org/10.1177/0265407500172005

Frijns, Tom, Catrin Finkenauer, Ad A. Vermulst, Ad A., and Rutger C. M. E. Engels. 2005. "Keeping Secrets from Parents: Longitudinal Associations of Secrecy in Adolescence." Journal of Youth and Adolescence 34, no. 2: 137-148. https://doi.org/10.1007/s10964-005-3212-z

Hables Gray, Chris. 2016. "Could Technology End Secrecy?" Secrecy and Society 1 , no. 1.

https://scholarworks.sjsu.edu/secrecyandsociety/vol1/iss1/6

Klyueva, Anna and Katerina Tsetsura. 2010. "Media Non-transparency Research: The Case of Romania." Public Relations Journal 4, no. 4: 124. https://apps.prsa.org/Intelligence/PRJournal/pasteditions/Vol4/No4/

Maret, Susan. 2016. "The Charm of Secrecy: Secrecy and Society as Secrecy Studies." Secrecy and Society 1, no. 1. https://scholarworks.sjsu.edu/secrecyandsociety/vol1/iss1/1 
Nagle, Ryen J. 2013. "College Teaching Behaviors of Community College Faculty." PhD diss., University of Illinois at Urbana-Champaign.

Paxman, Christina. 2013. "Adopting Frank Warren's PostSecret Art Project to Illustrate the Role of Secrets in Interpersonal Communication." Communication Teacher, 27, no. 4: 1-6. https://doi.org/10.1080/17404622.2013.798013

Simmel, Georg. 1906. "The Sociology of Secrecy and of Secret Societies." American Journal of Sociology 11, no. 4: 441-498. https://www.jstor.org/stable/2762562

Scott, Craig R. 2013. Anonymous Agencies, Backstreet Businesses, and Covert Collectives: Rethinking Organizations in the $21^{\text {st }}$ Century. Stanford, CA: Stanford University.

Slepian, Michael L., Jinseok S. Chun, and Malia F. Mason. 2017. "The Experience of Secrecy." Journal of Personality and Social Psychology 113, no. 1: 1-33. https://doi.org/10.1037/pspa0000085

Stanglin, Doug. 2018. "Why Releasing the Super-Secret Nunes Memo is so Divisive: What You Need to Know." USA Today, February 1, 2018. https://www.usatoday.com/story/news/2018/02/01/whats-behindclashes-over-super-secret-house-memo-here-what-you-needknow/1085902001/

Stohl, Cynthia and Michael Stohl. 2011. "Secret Agencies: The Communicative Constitution of a Clandestine Organization." Organization Studies 32, no. 9: 1197-1215. https://doi.org/10.1177/0170840611410839

Tax Justice Network. 2018. "Financial secrecy index." https://www.financialsecrecyindex.com/en/

Vangelisti, Anita, John Caughlin, and Lindsay Timmerman. 2001. "Criteria for Revealing Family Secrets." Communication Monographs 68, no. 1: 127. https://doi.org/10.1080/03637750128052

Warren, Frank. 2005. PostSecret: Extraordinary Confessions from Ordinary Lives. New York: Harper Collins. 


\section{Appendix}

Key aspects of syllabus for 1-credit course on Secrecy and Communication:

\section{Course Objectives}

Students completing this course should be able to do the following upon completion:

- Name and describe key ideas connected to secrecy and related terms

- Be able to talk about pros and cons of secrecy and transparency

- Gather basic data/research and/or critically analyze content to draw conclusions about secrecy issues

- Effectively communicate findings about secrecy issues

\section{Simple Course Calendar and Due Dates}

\begin{tabular}{|lll|}
\hline \multicolumn{1}{|c|}{ Week } & \multicolumn{1}{c|}{ Topic } & \multicolumn{1}{c|}{$\begin{array}{c}\text { Readings/ Posts/ Other } \\
\text { Due Dates }\end{array}$} \\
\hline $01 / 18 / 20$ & Introduction to Course & \\
\hline $1 / 25$ & $\begin{array}{l}\text { Communication and Secrecy } \\
\text { Overview }\end{array}$ & $\begin{array}{l}\text { *Post Self Intro - Revealing } \\
\text { Yourself }\end{array}$ \\
\hline $2 / 1$ & $\begin{array}{l}\text { Shadowy Revelations: Leaks } \\
\text { and Exposes }\end{array}$ & *Post on reading \\
\hline $2 / 8$ & Silence Breakers & *Post Online Secret \\
& & \\
\hline $2 / 15$ & $\begin{array}{l}\text { Studying Secrecy - Final } \\
\text { Project Assigned }\end{array}$ & *Post Research Article \\
& & Summary \\
\hline
\end{tabular}




\begin{tabular}{|c|c|c|c|}
\hline $2 / 22$ & $\begin{array}{l}\text { Secret Societies and Hidden } \\
\text { Organizations }\end{array}$ & \multicolumn{2}{|c|}{ *Post on Reading } \\
\hline $3 / 1$ & $\begin{array}{l}\text { Hiding in the Light: Popular } \\
\text { Occulture }\end{array}$ & \multicolumn{2}{|c|}{ Research Proposal Due } \\
\hline $3 / 8$ & $\begin{array}{l}\text { Workplace Secrecy and } \\
\text { Visibility Management }\end{array}$ & \multicolumn{2}{|c|}{$\begin{array}{l}\text { *Post Summary of Secret } \\
\text { Organization }\end{array}$} \\
\hline \multicolumn{4}{|c|}{ SPRING BREAK } \\
\hline $3 / 22$ & $\begin{array}{l}\text { Movie anc } \\
\text { Wormwoc }\end{array}$ & \multicolumn{2}{|c|}{$\begin{array}{l}\text { *Post Summary of Wormwood } \\
\text { Ep. } 1\end{array}$} \\
\hline $3 / 29$ & \multicolumn{2}{|c|}{$\begin{array}{l}\text { Makeup Day (No Class unless we miss } \\
\text { a week earlier in semester)-Extra } \\
\text { Week to Finish Projects }\end{array}$} & \\
\hline $4 / 5$ & $\begin{array}{l}\text { Presentations and Viewing of } \\
\text { Findings }\end{array}$ & $\begin{array}{l}\text { Final } \mathrm{Pr} \\
\text { Present } \\
\text { Class }\end{array}$ & $\begin{array}{l}\text { esentations; Copy of } \\
\text { ation Material Due in }\end{array}$ \\
\hline
\end{tabular}

\section{Assignments}

\begin{tabular}{|l|c|}
\hline $\begin{array}{l}\text { In-class participation. Every class period we meet we will } \\
\text { evaluate your participation in our discussion and in-class } \\
\text { activities. Come prepared to talk about things! }\end{array}$ & $25 \%$ \\
\hline $\begin{array}{l}\text { Online posts. By the start of each class, students will be } \\
\text { asked to make an online post to the course website about } \\
\text { either key takeaways from the reading assigned or a summary } \\
\text { related to the experiential activity one was doing. }\end{array}$ & $25 \%$ \\
\hline $\begin{array}{l}\text { Project Proposal. Each student/team will select a secrecy } \\
\text { topic and then write up a proposal } \\
\text { and a procedure they would use to explore this issue. This 2- } \\
\text { page paper includes at least one reference from beyond class } \\
\text { (assignments details to be provided). }\end{array}$ & $20 \%$ \\
\hline
\end{tabular}


Bratich and Scott: Challenges of Teaching Secrecy

\begin{tabular}{|c|c|}
\hline $\begin{array}{l}\text { Project Presentation. A 4-5 minute formal presentation or } \\
\text { recorded video of research findings, presented to the class } \\
\text { with some } Q \& A \text {. This includes written PowerPoint or similar } \\
\text { and must incorporate at least two references from beyond the } \\
\text { class (assignment details to be provided). }\end{array}$ & $30 \%$ \\
\hline TOTAL & $100 \%$ \\
\hline
\end{tabular}

